\title{
Challenges for integrated early warning and disaster management in the UAE
}

\author{
A. Al Hmoudi \& Z. Aziz \\ University of Salford, $U K$
}

\begin{abstract}
In the UAE, there are deficiencies in the use of technology in the exchange of information and reliance on the National Centre for Meteorology and Seismology Monitoring and Warning (NCMS). The new centre is affiliated to the Ministry of Presidential Affairs and it is established in coordination with concerned authorities. It is networked with similar centers in the region for the sharing of information and intervention at times of need. It also provides meteorology monitoring with advice and warning on storms. However, members of the community are uninformed and do not know the procedures carried out in the event of the arrival of early warning signals. The UAE is vulnerable to the possibility of tsunami activity. Early warning systems (EWS) within the UAE face various socio-technical challenges. Moreover, there are shortcomings in the training process and scenarios with individuals and institutions of civil society. Natural disaster management is not only about shelters and distribution of blankets, medicines and evacuation operations. It is also about education, awareness generation, mitigation strategies, community participation and lifestyles.
\end{abstract}

Keywords: early warning, challenges, community, natural hazards, disaster management, NCMS, communication.

\section{Introduction}

The United Nations International Strategy for Disaster Reduction (UN/ISDR) identified the use of custom-made caution messages for all inclusive groups as one of the four vital elements of early warning systems. Despite this, the element is seldom accounted for by hazard observation and early warning systems (EWS). In corporation with climate change-related vulnerability and risk assessment, the assessment of the risks should encompass both climate scenarios 
and a combination of hazard and vulnerability scenarios. This is a move to provide a solid decision making set up. (Birkmann et al. [1]). As highlighted by Renn and Walker [2] risk communication is considered a key element by the Integrated Risk Governance Structure in relation to risk control. Effective risk communication should serve the purpose to educate stake holders and the society in general the basis of risk and equip them with ability to make proper decisions in relation to risk. Effective communication between all the stake holders involved is considered a vital mechanism in approaching risk and should in relation improve awareness and effectual approach to risks (Chang-Seng and Jury [3]). According to Grasso et al. [4], the UN certainty of data should be efficiently conversed to the users. In addition, the people at risk should be timely warned on UN certainties (Birkmann et al. [1]; Chang-Seng and Jury [3]; DKKV and ISDR [5].The degree of consideration given to natural hazards such as floods, tropical storms and weather related hazards such as heavy precipitation and heat waves in comparison to slowly creeping hazard processes, for instance, salinisation and rises in sea-level, the main consideration lies on the natural hazards. In addition even lesser consideration has been given to accumulated shocks from non-extreme events (Birkmann et al. [1]). The major challenge in improving the ability of societies to manage environmental shocks and creeping environmental changes, is to craft an integrated structure that takes into account all relevant hazards without sidelining UN connected systems. This all inclusive approach should offer synergies and cost efficiencies, for instance in data gathering and processing, and in public preparedness endeavors. Additionally, it should aid in the enhancing and upholding warning abilities for the less frequent hazards, such as tsunamis (Basher [6]).

EWS within the UAE faces various socio-technical challenges: Firstly, the role of communities within EWS is not clearly defined. Also, members of the community are uninformed and unaware of Federal plan, and as results do not know the procedures carried out in the event of the arrival of early warning signals. Dhanhani [7] has highlighted how lack of an end to end and peoplecentered approach on EWS, low levels of preparedness and a general lack of knowledge regarding the emergency management plans. Secondly, the UAE has a huge expatriate population who do not speak Arabic. The presence of other languages, such as English, Persian, Hindi, and Urdu create significant communication challenges. As identified by Al Ameri [8], there are significant weaknesses in the transfer of understandable warning messages and preparedness information to those at risk and there are no networking and communication among the NCMS and other stakeholders.

\section{Reviewing the National Center of Meteorology and Seismology in the UAE}

The center is affiliated to ministry of presidential affairs which is the authority concerned with meteorology and seismology affairs. It represents the country as a member in the world organization for meteorology and seismology. The center provides services to the public, governmental bodies, research centers, media, 
and aviation and decision makers. The federal decree number 6 of 2007 was promulgated to establish and regulate the National Center of Meteorology and Seismology (NCMS [9]). Main fields of the National Center of Meteorology and Seismology: the introductory handout issued by the National Center of Meteorology and Seismology illustrates that it is concerned with the following fields (NCMS [9]). Meteorology and Early Warning: the center works within the global system of the World Organization of Meteorology in international and regional collaboration with member states of the above mentioned organization. It performs its tasks through the following organizations and abilities:

1. Weather networks: the center operates and maintains 59 automatic weather stations all over the world, 5 weather radars and upper atmosphere layers station.

2. Communication network: all meteorological information is to be collected and exchanged through local, regional and international communication networks. The Center is connected with the following main circles: Abu Dhabi/Muscat, Abu Dhabi/Jeddah, satellite circles and uses MSS system to collect and redistribute data.

3. Weather forecasting includes: main forecasting center, numeral forecasting center, in which a high resolution (HRM) model and its applications (SWAM MAM) are used while (Visual Weather) is used to follow weather changes, flight forecasting and naval forecasting centers.

4. Rain-making applications: the center has two flights working in rain-making project and assisted by 5 earth radars. Many good experiments have been conducted in this field. This field is one of the main activities of the center.

5. Climatic studies: the center reviews and processes climatic data, and prepare climatic studies and reports serving activities in different countries, especially those concerned with studies and researches such as universities, research institutions and entities concerned with applied sides and establishing climatic information bank.

6. In an earthquake's field: the center, through a network of five stations for monitoring strong and weak movement of earthquakes, conducts monitoring works. Such stations are the same as those stations used in earthquakes monitoring network for nuclear experiments comprehensive banned area. Also, the center is specialized in earthquake engineering studies, applied geology and the effect of soil on earthquakes waves.

\subsection{Research, developing and training fields}

The center is to perform scientific research, especially applied ones in forecasting and seismology; to participate in the universities, research institutes and related studies; to train the needed technical cadres to work in forecasting and seismology.

\subsection{Technical services field}

A department was established in the center for delivering technical services for managing databases and systems; creating, developing and analyzing databases 
programming; managing and maintaining communication lines and networks; maintaining forecasting and earthquakes equipment and devices. The center should work to provide all the developed devices and equipment for every section coping with the new developed technologies.

\section{Methodology}

According to the four elements of an early warning system explained previously, the second stage is disaster observation. The National Center of Meteorology and Seismology plays a vital role with respect to observation, weather forecast and prediction process, which is the essence of early warning system. The researcher has focused on explaining and studying the National Center of Meteorology and Seismology in Abu Dhabi which, subjects to ministry of presidential affairs. A random sample was taken from the center's staff to determine how staff understands their role and needs of early warning system, and the availability modern technology means to early warning system and natural disaster observation.

\subsection{Survey results}

The study was conducted on a sample consists of (40) persons from workers in the National Center of Meteorology and Seismology, in UAE. Researcher followed certified scientific approaches and frames in selecting the sample for study. Results are as follows:

Table 1: Sample age groups.

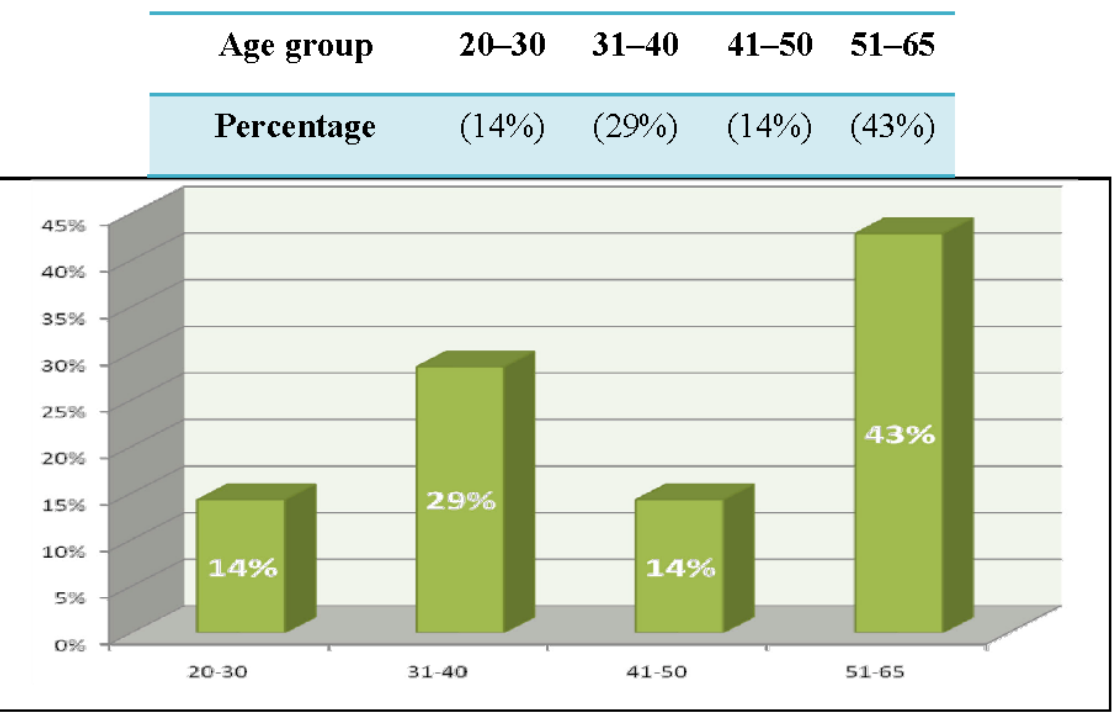


Table 2: Satisfaction average with current weather forecast pattern performance and efficiency.

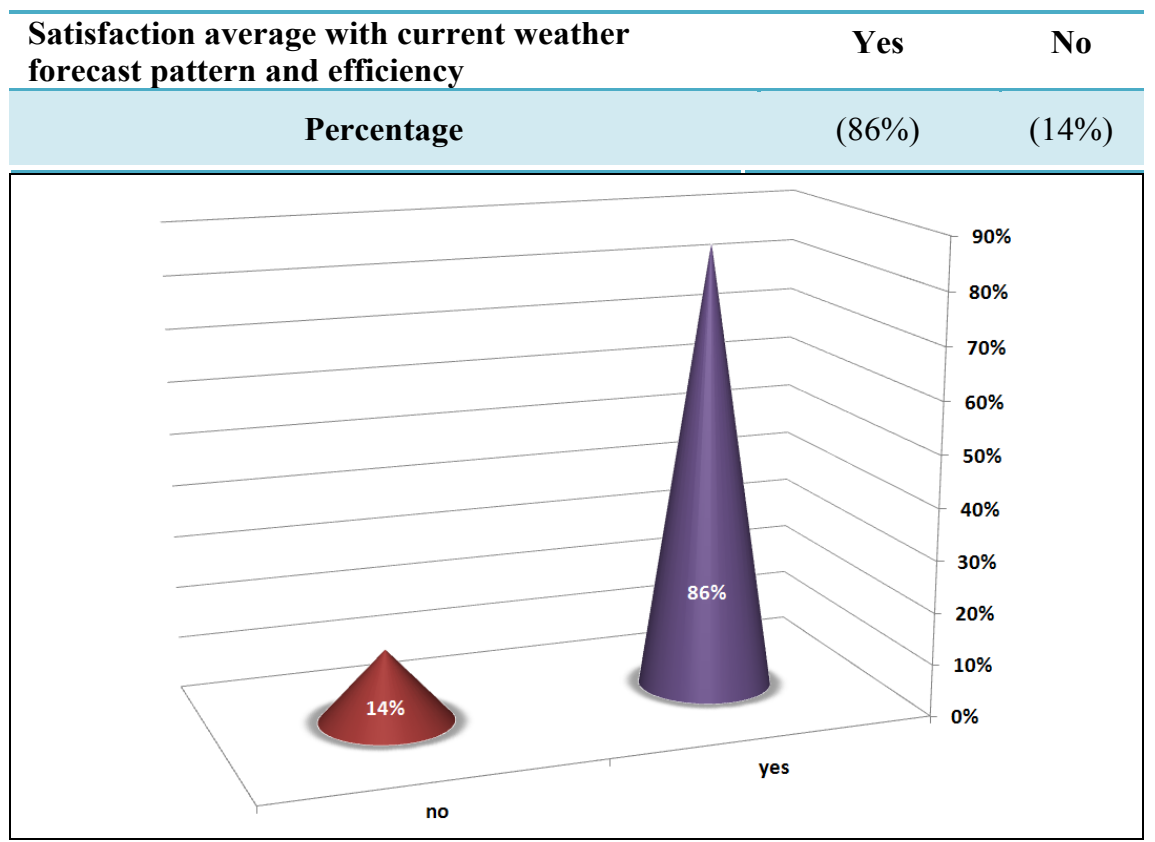

The study showed that 6 persons $(86 \%)$ from the sample of study are satisfied with current weather forecast pattern performance and efficiency. On the other hand, only one person, (14\%) from the sample is not.

The study showed that 6 persons $(86 \%)$ of the studied sample are satisfied with the current tsunami forecast pattern performance and efficiency. While only one person $(14 \%)$ is not.

The researcher found, after his visit to the National Center of Meteorology and seismology; the best way of coordination between the Center and the Department of Emergency and Public Safety, is by exchanging field visits to get familiar with the work nature of each other, and exchanging data and experience. Researcher suggests appointing a deputy from the Centre in the Central Operation room in the General Directorate of Abu Dhabi Police, to provide the required information about weather updates and to explain its details, as he is the specialized person for weather conditions observation.

\section{Challenges of EWS pertaining to new environmental shocks in the UAE}

The policy lessons that can be emulated from existing EWS and monitoring in the context of dissimilar and exposed target groups in the National Center of Meteorology and seismology (UAE) are sum up as follows. 
Table 3: Satisfaction average with current tsunami forecast pattern performance and efficiency.

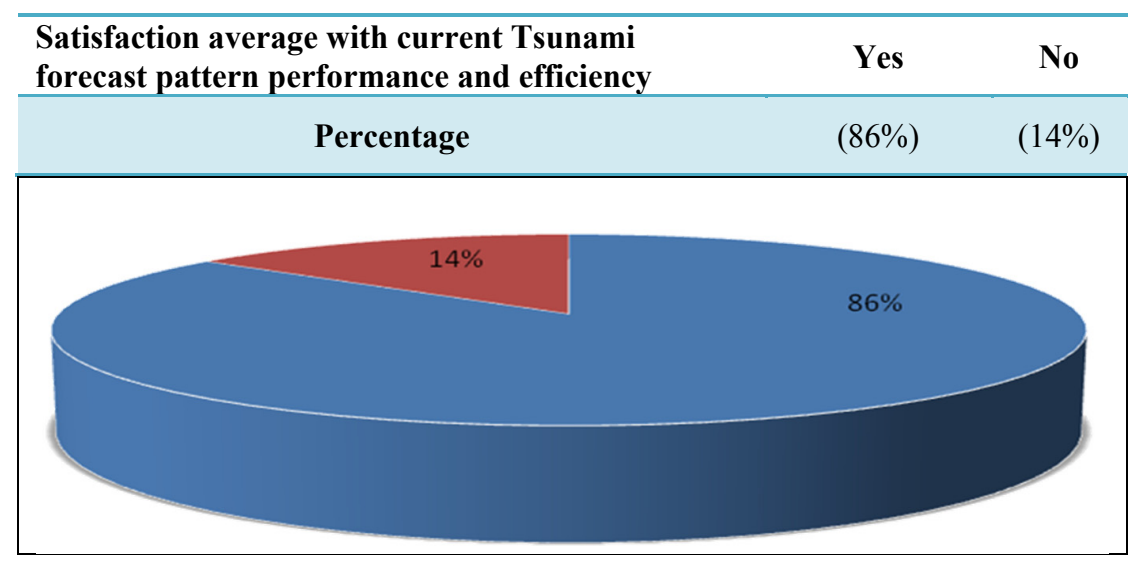

- $\quad$ So as to prop up resilience building, the focus on EWS should not only be hazards but also on the notion of exposure. There is need for EWS to be improved so that people are not only warned before the event of a hazard impacts a society, but also have a say in making sure that the livelihoods/lives at risk are secure from the gradual changes that are brought by climate changes.

- There is need for information on hazard pattern changes to be merged with knowledge and forecasts about the development of vulnerabilities. The combination of the two will present the foundation of high quality EWS.

- There is no sustainability in isolated or individual hazard, especially in the context of dealing with the challenges related to climate change. This calls for the need to give an explanation for rapid and gradual hazards simultaneously (for example, the potential significance of storm surges and sea-level rise)

- Top-down, technocratic, expert-driven and linear EWS alone are not effective at reducing damage and saving lives. A mixed institutional approach that includes both formal and informal phases is frequently indispensable. In such a scenario, the system does not control the people at risk but the people are an essential part of the system, thus creating a people-cantered approach. This entails combining different types of knowledge in EWS, especially by connecting scientific and traditional knowledge.

- The development process of EWS entails a multi-disciplinary approach. This approach must recognize all the stakeholders in the community and along the chain. It must also strive to build partnership and dialogue instead of being based on a top-down alert process. 
- The human assets and preparedness approaches connected to a EWS are especially imperative in low-technology places.

- There is supposed to be a change towards working, relating and communicating 'with' the community as opposed to 'for' the community.

- The shift of EWS technologies in dissimilar societal and cultural settings raises the question of robust and the abilities of the societies' to uptake such complicated technologies devoid of deal with the digital divide governance problem.

- In addition, the new technologies and communication platforms like Face book and Twitter and the internet generally have to be understood better. This is in terms of their role in enlightening and warning people in situations of calamity.

- The effectiveness and sustainability of a EWS is driven by the systems of governance, which is economic, political and socio-technological.

- The founding and development of EWS should be an essential objective of both rural and urban planning ad connected sectors.

- So far, EWS have been very effective in identifying sudden-onset hazards at the same time creeping societal tipping points and environmental changes that are imperative dynamics in decisions to migrate. In terms of displacement, EWS have not been adequately well thought-out, or at least have gotten not as much of interest compared to hazard detection

- Currently, climate services are under development through the GFCS (Global Framework for Climate Services). In this situation, the lack of effective climate services around the world restricts the current abilities and prospects in the use of climate information for EWS.

\section{Summary}

Early warning is to give the opportunity of time to prepare and to reduce the confrontation of the victims, and reduce the economic and social losses in the United Arab Emirates. National Centre for Meteorology and Seismology in the UAE the national main responsible for the establishment of an early warning system in the state, in coordination with the concerned authorities, including the Ministry of Interior represented emergency management; public safety and civil defense. And coordination between them contributes to overcoming the challenges facing early warning in the UAE.

\section{References}

[1] Birkmann, J., Chang Seng, S.D., Surez, D. (2011). Adaptive Disaster Risk Reduction in the Light of Climate Change, Ed DKKV. 
[2] Renn, O. and Walker, K. (2007) Lessons learned: a re-assessment of the IRGC framework on risk governance. In: Renn, O. and Walker, K. (eds.) the IRGC Risk Governance Framework: Concepts and Practice. Springer, Heidelberg and New York, pp. 331-367.

[3] Chang-Seng, D. and Jury, M. (2010): Tropical cyclones in the SW Indian Ocean. Part 2: structure and impacts at the event scale. In: Meteorology and Atmospheric Physics. vol. 106, no. 3, pp. 163-178.

[4] Grasso V.F., Beck J. and Manfredi G. (2007). Automated decision procedure for earthquake early warning, Journal of Engineering Structures, 29 (Issue 12), pp. 3455-3463.

[5] ISDR. (2009). "Reducing Disaster Risks through Science: Issues and Actions. Report of the ISDR Scientific and Technical Committee". Global Platform for Disaster Risk Reduction, in Geneva, Online 10/03/2010 http://www.preventionweb.net/globalplatform/2009/background/documents/ SD-03-ENGScientific-Technical-Committee.pdf.

[6] Basher, R. (2006). Global early warning systems for natural hazards: Systematic and people-centered. In: Philosophical Transactions of the Royal Society 364: pp. 2167-2182.

[7] Dhanhani, H. (2010) Evaluation of the Response Capability of the United Arab Emirates to the Impact of Natural Hazards.

[8] Al Ameri, F. (2010). Implementing an Effective Public Warning System in Abu Dhabi UAE. Coventry University (MSC-Disaster Management).

[9] National Center of Meteorology and Seismology (NCMS), (2013). Ministry of Presidential Affairs, UAE. 